\title{
THE POSITION OF THE REACTIVE SITE PEPTIDE BOND IN EGGPLANT TRYPSIN INHIBITOR MOLECULE ${ }^{1}$
}

\author{
Fumio IBUKI, ${ }^{2}$ Makoto KotAru, ${ }^{2 *}$ Akihiko KATSUradA, ${ }^{2}$ \\ Toshio AsAo, ${ }^{3}$ Misao TASHIRO, ${ }^{2 * *}$ \\ and Masao KANAMORI ${ }^{2}$ \\ ${ }^{2}$ Department of Agricultural Chemistry, Faculty of Agriculture, \\ Kyoto Prefectural University, Kyoto 606, Japan \\ ${ }^{3}$ Department of Food Science, Faculty of Home Economics, \\ Mukogawa Women University, Nishinomiya 662, Japan
}

(Received December 28, 1979)

\begin{abstract}
Summary The purified trypsin inhibitor from eggplant (Solanum melongena, L.) has an Arg-X bond in the reactive site which is selectively cleaved by limited hydrolysis with a catalytic amount of bovine trypsin. So-called trypsin-modified inhibitor was separated from the native one by QAE-Sephadex A-25 chromatography. After the cleavage of disulfide bonds of isolated modified inhibitor by means of reduction and $S$ carboxymethylation, two fragments (F-I and F-II) were obtained by gel filtration on Sephadex G-25. F-I and F-II were composed of 44 and 14 amino acid residues, respectively. The sum of both coincided with that of the native inhibitor. The N-terminal of F-I was blocked and the Cterminal was arginine. In F-II, the $\mathrm{N}$-terminal was identified as asparagine and the $\mathrm{C}$-terminal as serine. No $\mathrm{N}$-terminal amino acid could be detected in the native inhibitor, as described in our previous paper (7). Therefore, it is concluded that the reactive site of eggplant trypsin inhibitor is an arginylasparagine bond located between residues 44 and 45.
\end{abstract}

Keywords reactive site, eggplant, trypsin inhibitor, Solanum melongena, L., modified inhibitor

1 This paper was partially communicated at the annual meeting of the Agricultural Chemical Society of Japan held in Tokyo on April 4th 1979.

2 伊吹文男, 小垂 真, 桂田昭彦, 田代 操, 金森正雄, ${ }^{3}$ 浅尾俊夫

* Present address: Faculty of Home Economics, Koka Women's Junior College, Kyoto 615, Japan.

** Present address: Department of Food Science, Faculty of Living Science, Kyoto Prefectural University, Kyoto 606, Japan. 
The occurrence of trypsin inhibitors in eggplant, Solanum melongena, L.(1), together with its purification and some properties have been studied in our laboratory (2-5). It is well known that naturally occurring trypsin inhibitors have either an Arg-X or Lys- $X$ trypsin-sensitive bond in their reactive site (6).

The chemical modification of arginine residues in the eggplant trypsin inhibitor (ETI) caused a marked decrease of inhibitory activity against trypsin (7). Furthermore, an arginine residue was exposed as a new C-terminal in the so-called modified ETI of which the reactive site peptide bond was cleaved by limited hydrolysis with trypsin(7). The reactive site of the inhibitor against trypsin was concluded to be an Arg-X from these results. However, the position of the reactive site in the ETI molecule has not yet been determined. This paper deals with the fragmentation of the trypsin-modified ETI by cleavage of its disulfide bonds, and the position of the reactive site in the inhibitor molecule.

\section{MATERIALS AND METHODS}

Materials. ETI was prepared by the method described previously (5). Tryp$\sin$ [EC 3.4.21.4] (twice crystallized, from bovine pancreas) and carboxypeptidase B [EC 3.4.12.3] (DFP treated, from hog pancreas) were purchased from Sigma Chemical Co. Carboxypeptidase P (crystallized from Penicillium janthinellum) was a product of Takara Shuzo Co., Ltd. (Shiga, Japan). $\alpha-N$-Benzoyl-D,L-arginine $p$ nitroanilide (BApNA) was obtained from Protein Research Foundation (Osaka, Japan). All other chemicals were of special or reagent grade.

Methods. Trypsin and trypsin inhibitory activities were assayed by the spectrophotometric method using BApNA as substrate as described in our previous paper (1). Amino acid analyses were performed with an Hitachi KLA-5 automated amino acid analyzer. The protein was hydrolyzed in $6 \mathrm{~N} \mathrm{HCl}$ at $110^{\circ} \mathrm{C}$ in an evacuated and sealed tube for $24 \mathrm{hr}$. N-Terminal and sequential amino acid analyses from the $\mathrm{N}$-terminal were performed by Edman degradation according to the method of Iwanaga et al. (8). The phenylisothiohydantoin (PTH) derivative was identified by thin-layer chromatography (9).

Carboxypeptidase $\mathrm{B}$ treatment was performed at a molar ratio of substrate: enzyme of $100: 1$ by the method of Ambler (10). Carboxypeptidase P digestion was carried out at the molar ratio of $250: 1$ according to the method of Yokoyama et al. (11). TPCK [L-(1-tosylamido-2-phenyl)ethyl chloromethyl ketone]treated trypsin was prepared by the procedure of Carpenter (12).

\section{RESULTS}

Modification of eggplant trypsin inhibitor by limited hydrolysis with trypsin

The inhibitor $(100 \mathrm{mg})$ was dissolved in $20 \mathrm{ml}$ of $0.2 \mathrm{M} \mathrm{KCl}-\mathrm{HCl}$ buffer, $\mathrm{pH}$ 2.5 , containing $0.1 \mathrm{M} \mathrm{CaCl}_{2}$. To this solution, $10 \mathrm{mg}$ of TPCK trypsin (molar ratio $50: 1$ ) was added and the $\mathrm{pH}$ was adjusted to 2.5 with $0.1 \mathrm{M} \mathrm{HCl}$. The mixture was 
incubated for $48 \mathrm{hr}$ at $25^{\circ} \mathrm{C}$ maintaining the $\mathrm{pH}$ at 2.5 with a $\mathrm{pH}$-stat RTS Radiometer, Copenhagen. After modification, the reaction mixture was subjected to gel filtration on a Sephadex G-50 column $(2.5 \times 100 \mathrm{~cm})$ equilibrated with the same buffer to remove trypsin. Consequently, two peaks were obtained as shown in Fig. 1. The first peak had trypsin activity and the second peak was the inhibitor fraction.

Figure 2 shows the time-course of trypsin-modified inhibitor formation

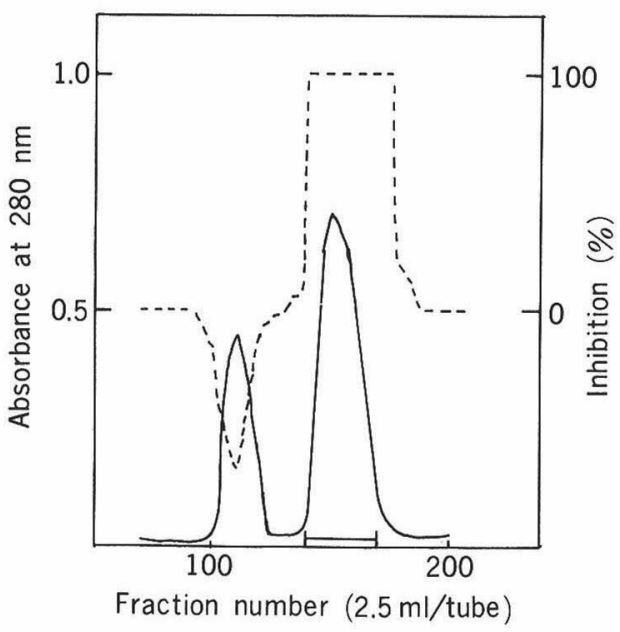

Fig. 1. Gel filtration of trypsin-modified ETI on Sephadex G-25 to remove added trypsin. The reaction mixture was applied on a column $(2.5 \times 100 \mathrm{~cm})$ and eluted with $0.25 \mathrm{M} \mathrm{KCl}-\mathrm{HCl}$ buffer, $\mathrm{pH} 2.5$, containing $0.1 \mathrm{M} \mathrm{CaCl}_{2}$ at a flow rate of $27.5 \mathrm{ml} / \mathrm{hr}$. The fractions shown by the bar were collected. - , absorbance at $280 \mathrm{~nm} ;------$, trypsin inhibitory activity.

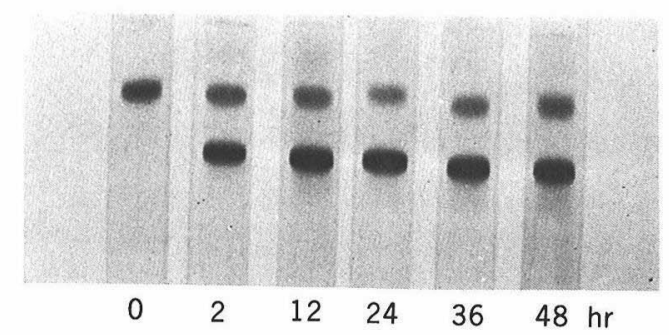

Fig. 2. Time-course of the reaction of limited hydrolysis of ETI monitored by disc electrophoresis. Disc electrophoresis was carried out at $\mathrm{pH} 9.4$ in $7.7 \%$ polyacrylamide gel. A current of $3 \mathrm{~mA}$ per tube was supplied for $1 \mathrm{hr}$. After dyeing the gels with amino black 10B, the concentration of each band was measured by scanning using Shimadzu two wave-length chromatoscanner, CS-900. 
monitored by disc polyacrylamide gel electrophoresis according to the method of Davis (13). The trypsin-modified inhibitor corresponds to a band showing faster electrophoretic mobility. After $48 \mathrm{hr}, 70 \%$ of native inhibitor was converted into the modified one.

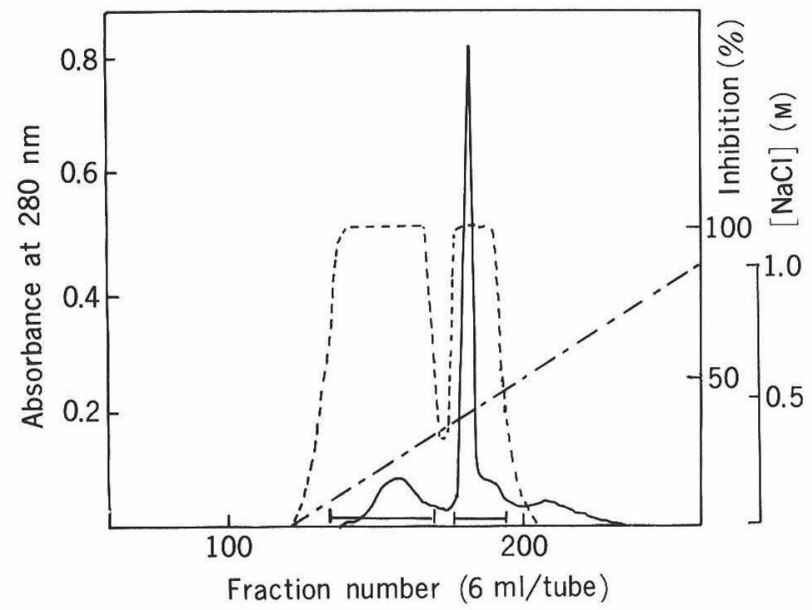

Fig. 3. The separation of native and modified ETI by QAE-Sephadex A-25 column chromatography. The lyophilized sample obtained from gel filtration (Fig. 1) was applied on a column $(2.5 \times 38 \mathrm{~cm})$ of QAE-Sephadex A- 25 and the proteins were eluted with a $\mathrm{NaCl}$ linear gradient system $(0-1.0 \mathrm{M})$ in $0.05 \mathrm{M}$ borate- $\mathrm{KCl}-\mathrm{NaOH}$ buffer, $\mathrm{pH} 9.0$. The flow rate was $29 \mathrm{ml} / \mathrm{hr}$. The fractions represented by bars were collected for further experiments. —-, absorbance at $280 \mathrm{~nm}$; ------, trypsin inhibitory activity; -- - $\mathrm{NaCl}$ concentration.

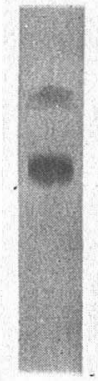

(1)

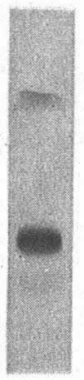

(2)

Fig. 4. Disc electrophoretic patterns of fractions obtained from QAE-Sephadex A-25 chromatography (Fig. 3). Disc electrophoresis was carried out with the same condition as described in Fig. 2. (1) The sample from the first peak in Fig. 3. This corresponds to the native inhibitor. (2) The sample from the second peak in Fig. 3. This corresponds to the modified inhibitor. 


\section{Isolation of the modified inhibitor}

The fraction represented by the bar in Fig. 1 was collected and dialyzed against $0.05 \mathrm{M}$ borate- $\mathrm{KCl}-\mathrm{NaOH}$ buffer, $\mathrm{pH} 9.0$, using the acetylated cellulose tube (5). The dialyzate was applied on a QAE-Sephadex A-25 column $(2.5 \times 38 \mathrm{~cm})$ equilibrated with the same buffer and the column was washed with a sufficient amount of the buffer and then the protein was eluted by a linear gradient system containing $\mathrm{NaCl}(0-1.0 \mathrm{M})$ in the same buffer. The elution profile is shown in Fig. 3. Two protein peaks having inhibitory activity were gained. Each peak shown by bars was collected, desalted by dialysis and lyophilized. The results of disc electrophoresis of each peak indicated that the first peak in Fig. 3 was a native inhibitor and the second peak corresponded to the modified one (Fig. 4).

\section{Reduction and S-carboxymethylation of modified inhibitor}

In order to identify the position of the reactive site in the inhibitor molecule, fragmentation of the modified ETI was attempted. For the purpose of this work, reduction and $S$-carboxymethylation of the modified inhibitor were carried out by the method of Crestfield (14).

Modified ETI $(50 \mathrm{mg})$ was dissolved in $8 \mathrm{ml}$ of $8 \mathrm{M}$ urea containing $0.2 \%$ ethylenediamine tetraacetic acid at $\mathrm{pH}$ 8.5. To the solution, 2-mercaptoethanol was added and the $\mathrm{pH}$ adjusted and maintained at 8.0 at $25^{\circ} \mathrm{C}$ for $4 \mathrm{hr}$ under nitrogen gas. The subsequent carboxymethylation was carried out with monoiodoacetic acid in the dark maintaining the $\mathrm{pH}$ at 8.0. After termination of the reaction, glacial acetic acid was added to make the $\mathrm{pH}$ 4.0. Sufficient amounts of $\mathrm{SH}$ and alkylating reagents (almost 50-fold excess of sulfhydryl residue) were used in those experiments.

The reaction mixture was applied on a Sephadex G-25 column wrapped with aluminum foil $(2.5 \times 100 \mathrm{~cm})$ and equilibrated with $0.2 \mathrm{M}$ acetic acid and then proteins were eluted with the same solution. Figure 5 shows the elution profile. Two peaks were detected by a monitor of absorbance at $280 \mathrm{~nm}$. The first peak was designated F-I and the second peak, F-II.

\section{Amino acid analyses of F-I and F-II}

Table 1 indicates the amino acid composition of two fragments derived from the modified ETI compared with that of the native inhibitor. The sum of each amino acid residue of F-I and F-II completely coincided with those of the native one. This result indicates that only the reactive site was cleaved by this trypsin modification.

\section{$N$ - and C-terminal amino acid of $F-I$}

The N-terminal amino acid of F-I could not be detected by Edman degradation. After treatment of F-I with carboxypeptidase B at $37^{\circ} \mathrm{C}$ for $24 \mathrm{hr}$, a stoichiometric amount of arginine was released. As described in our preceding paper (7), no N-terminal amino acid was detected in the native inhibitor: This may 
Table 1. Amino acid composition of F-I and F-II compared with the native inhibitor.

\begin{tabular}{|c|c|c|c|}
\hline \multirow{2}{*}{ Amino acid } & \multicolumn{3}{|c|}{ Residues per molecule } \\
\hline & F-I & F-II & Native ETI (5) \\
\hline Lysine & $4.2(4)^{\mathrm{a}}$ & $0 \quad(0)$ & $4.0(4)$ \\
\hline Histidine & $0 \quad(0)$ & $\begin{array}{ll}0 & (0)\end{array}$ & $\begin{array}{ll}0 & (0)\end{array}$ \\
\hline Arginine & $1.6(2)$ & $1.0(1)$ & $2.8(3)$ \\
\hline Aspartic acid & $4.7(5)$ & $2.2(2)$ & $6.9(7)$ \\
\hline Threonine & $2.1(2)$ & $0 \quad(0)$ & $2.2(2)$ \\
\hline Serine & $3.2(3)$ & $0.5(1)$ & $3.5(4)$ \\
\hline Glutamic acid & $4.8(5)$ & $0 \quad(0)$ & $4.7(5)$ \\
\hline Proline & $4.3(4)$ & $0.9(1)$ & $5.0(5)$ \\
\hline Glycine & $4.4(5)$ & $2.1(2)$ & $7.0(7)$ \\
\hline Alanine & $1.4(2)$ & $1.3(1)$ & $3.1(3)$ \\
\hline Half-cystine & $6.6(6)$ & $2.1(2)$ & $8.4(8)$ \\
\hline Valine & $0 \quad(0)$ & $0 \quad(0)$ & $0 \quad(0)$ \\
\hline Methionine & $0 \quad(0)$ & $0 \quad(0)$ & $0 \quad(0)$ \\
\hline Isoleucine & $1.7(2)$ & $2.1(2)$ & $4.0(4)$ \\
\hline Leucine & $0.6(1)$ & $1.3(1)$ & $1.7(2)$ \\
\hline Tyrosine & $1.0(1)$ & $1.0(1)$ & $2.3(2)$ \\
\hline Phenylalanine & $2.2(2)$ & $0 \quad(0)$ & $2.2(2)$ \\
\hline Tryptophan ${ }^{\mathrm{b}}$ & $0 \quad(0)$ & $0 \quad(0)$ & $0 \quad(0)$ \\
\hline Total residues & (44) & (14) & $(58)$ \\
\hline Mol. wt. & 4,740 & 1,463 & 6,203 \\
\hline
\end{tabular}

${ }^{a}$ Numbers in parenthesis are the integers. ${ }^{b}$ Determined spectrophotometrically.

be the first indication of $\mathrm{N}$-blocked trypsin inhibitor in the plant kingdom. Consequently, F-I is concluded to be located in the N-terminal site of the native inhibitor molecule.

\section{$N$ - and C-terminal amino acid of F-II}

The C-terminal amino acid of F-II was identified to be a serine by carboxypeptidase $\mathrm{P}$ treatment. The sequential Edman degradation of F-II gave a partial amino acid sequence as Asn-Cys-Asp-Gly-Arg-Ile-Ala- from the $\mathrm{N}$ terminal. Considering the results of $\mathrm{N}$ - and $\mathrm{C}$-terminal analyses of both fragments, it is concluded that the reactive site peptide bond of ETI is an arginylasparagine bond located between residues 44 and 45 . 


\section{DISCUSSION}

Limited hydrolysis of ETI with a catalytic amount of trypsin at $\mathrm{pH} 2.5$ resulted in a selective cleavage of the reactive site peptide bond and ETI converted into so-called modified inhibitor very easily. As an equilibrium state exists between the native and modified inhibitor, the reaction mixture of enzymatic modification of the inhibitor contained both the native and modified inhibitor. To avoid some experimental problems caused by the presence of both inhibitors in the reaction mixture, a trial separation of them was attempted. Satisfactory separation was performed by QAE-Sephadex A-25 chromatography (Fig, 3). After the reduction and carboxymethylation of the modified inhibitor, two fragments, F-I and F-II were readily separated on gel filtration (Fig. 5). This means that the molecular weights of both fragments are different, and the position of the cleaved peptide bond corresponding to the reactive site should be located far from the center zone of the ETI molecule. Actually, the reactive site was located between residues 44 and 45 .

In our preceding paper(7), an arginylserine was reported as the reactive site peptide bond. It might be caused by the misidentification of a PTH amino acid derived from Edman degradation. While our work was in progress, Richardson recently reported the amino acid sequence and the reactive site of eggplant trypsin inhibitor prepared according to our method(15). However, a considerable

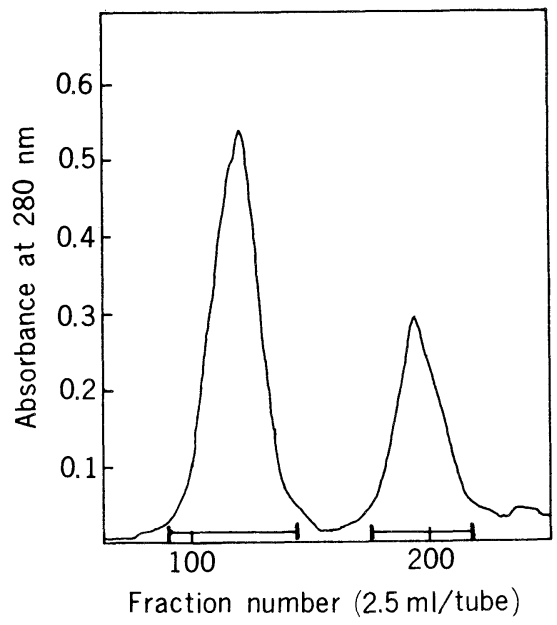

Fig. 5. Sephadex G-25 gel filtration of the modified ETI after reduction and carboxymethylation for the fragmentation. The sample was charged on a column $(2.5 \times 100 \mathrm{~cm})$ which was wrapped with aluminum foil and $0.2 \mathrm{M}$ acetic acid was used for the elution. Two fractions shown by the bars were collected and lyophilized. The elution was carried out at a flow rate of $30 \mathrm{ml} / \mathrm{hr}$. _ , absorbance at $280 \mathrm{~nm}$. 
discrepancy in the mutual total amino acid residues was observed. This discrepancy remains to be resolved.

The authors wish to express sincere thanks to Prof. Dr. T. Ikenaka, Department of Chemistry, Osaka University, for his invaluable suggestions in the Edman degradation method.

\section{REFERENCES}

1) Kanamori, M., Ibuki, F., Tashiro, M., Yamada, M., and Miyoshi, M. (1975): Occurrence of a trypsin inhibitor in eggplant exocarps. J. Nutr. Sci. Vitaminol., 21, 421-428.

2) Kanamori, M., Ibuki, F., Tashiro, M., Yamada, M., and Miyoshi, M. (1975): Several properties of the inhibitor in eggplant exocarps. J. Nutr. Sci. Vitaminol., 21, 429-436.

3) Kanamori, M., Ibuki, F., Yamada, M., Tashiro, M., and Miyoshi, M. (1976): Partial purification and some properties of the dialyzable proteinase inhibitor from the eggplant exocarps. Agric. Biol. Chem., 40, 839-844.

4) Kanamori, M., Ibuki, F., Tashiro, M., Yamada, M., and Miyoshi, M. (1976): Purification and partial characterization of a protein proteinase inhibitor isolated from eggplant exocarps. Biochim. Biophys. Acta, 439, 398-405.

5) Ibuki, F., Yamada, M., Tashiro, M., and Kanamori, M. (1977): An improved method for the purification of eggplant trypsin inhibitor. J. Nutr. Sci. Vitaminol., 23, 133-143.

6) Laskowski, M., Jr., and Sealock, R. W. (1971): Protein proteinase inhibitorsmolecular aspects, in The Enzymes, Vol. 3, Academic Press, New York, pp. 375-473.

7) Yamada, M., Tashiro, M., Yamaguchi, H., Yamada, H., Ibuki, F., Kanamori, M. (1976): The reactive site of eggplant trypsin inhibitor. J. Biochem. (Tokyo), 80, 1293-1297.

8) Iwanaga, S., Wallen, P., Grondahl, N. J., Henschen, A., and Blombach, B. (1969): On the primary structure of human fibrinogen. Eur. J. Biochem., 8, 189-199.

9) Koide, T. (1976): Sequence determination from N-terminal, in Seikagaku Jikken Koza, Vol. 1, Protein Chemistry II, ed. by The Japanese Biochemical Society, Tokyo Kagaku Douzin, Tokyo, p. 168.

10) Ambler, R. P. (1972): Carboxypeptidase A and B, in Methods in Enzymology, Vol. 25, ed. by Hirs, C.H.W., Academic Press, New York, pp. 262-272.

11) Yokoyama, S., Oobayashi, A., Tanabe, O., Ichishima, E. (1975): Action of crystalline acid carboxypeptidase from Penicillium janthinellum. Biochim. Biophys. Acta, 397, 443-448.

12) Carpenter, F. H. (1967): Treatment of trypsin with TPCK, in Methods in Enzymology, Vol. 11, ed. by Hirs, C.H.W., Academic Press, New York, p. 237.

13) Davis, B. J. (1964): Disc electrophoresis II, Method and application to human serum proteins,. Ann. N.Y. Acad. Sci., 121, 404-427.

14) Crestfield, A. M., Moore, S., and Stein, W. H. (1963): The preparation and enzymatic hydrolysis of reduced and $S$-carboxymethylated proteins. J. Biol. Chem., 238, 622-627.

15) Richardson, M. (1979): The complete amino acid sequence and the trypsin reactive (inhibitory) site of the major proteinase inhibitor from the fruits of aubergine (Solanum melongena L.). FEBS Lett., 104, 322-326. 